\title{
Trying times
}

These are trying times, both in terms of the trying, demanding circumstances brought on by the COVID-19 pandemic and in terms of how hard we are all trying to strike a balance between our regular duties and those required for living and working in this new virtual world. How do we strike a balance between our personal responsibilities and our professional ones? How do we choose between compelling but competing priorities such as keeping ourselves and our families safe, continuing to do our "regular" jobs, meeting our students' needs, transitioning our courses to online learning platforms, keeping our research going, functioning in web-based meeting applications, and maintaining some sense of well-being? In addition to wondering how to maintain balance, we are worried about our academic institutions. We are grappling with pressure from our institutions that, in some cases, questions our very qualifications as we express concern about the best path forward (Flaherty, 2020; Weliever, 2020). As a community, we can work not only to take care of ourselves but also to help stand up for and support one another as ASEE President Stephanie Adams recently did (American Society for Engineering Education, 2020).

As the editor and deputy editors of the Journal of Engineering Education (JEE), we have been going through an existential crisis as well. We are sensitive to the extra stress that our associate editors, authors, and reviewers are experiencing. As deadlines came and went, we found ourselves asking one another, how does our work fit into the big picture anyway? How should JEE respond to this crisis?

In thinking through an appropriate response to COVID-19 for an education research journal, we felt a lot was at stake and that our messaging had to be just right. We could put out a call for COVID-19 pandemic-related papers, but we did not want to send the message that $J E E$ is asking faculty and administrators to add to their already overfull plates. We did not expect people to pore over research papers about online learning and evidence-based practices, nor did we expect people to begin new research related to the COVID-19 pandemic when we are all just doing the best we can to survive. But we did not want to lose an opportunity to help our community respond, when the time is right, by reflecting on and researching the myriad ways COVID-19 has affected engineering education. So we crafted a two-stage response. The first stage-our immediate response-is to compile a virtual issue of $J E E$ articles about online and virtual learning environments from the past 10years: https://onlinelibrary.wiley.com/doi/toc/10.1002/(ISSN)2168-9830. Online-Learning-Simulations-Virtual-Learning-Environments. We hope this is a helpful resource for those with the time and motivation to examine the evidence for best practices in online learning, for example, how students function on virtual teams or how computer simulations can be used as learning tools.

The second stage in our response is a call for papers for a special themed section of a future issue of JEE, to be tentatively published in January 2022, that reflect on how the pandemic has affected students, educators, teaching, and learning, and the engineering education community broadly. Topics could include, but are not limited to, new knowledge about learning, virtual learning environments, the impact of stress on learning, and virtual collaborations among stakeholders in the engineering education community. Other broader topics could include sociocultural issues related to access to technology that enables online education and critical analyses of how engineering education prepares individuals for global crises such as COVID-19. For more information, see the call for papers posted here: https://onlinelibrary. wiley.com/pb-assets/assets/21689830/JEE\%20CALL\%20FOR\%20PAPERS\%20-\%20COVID19\%20v2-1588693190370.pdf.

This pandemic has brought important issues to the forefront that we could ignore in previous times, particularly those related to inequalities in access to education. Quarantining and remote instruction have both amplified the limited access some of our students have to resources and revealed-literally, through video conferencing into our students' homes-how many burdens they are carrying even when things are "normal." Educators, administrators, and staff at universities are struggling with similar issues. These inequities are likely to continue to oppress and further marginalize people within the academy, amplifying divisions between those of us with and without privilege. Linda Vanasupa's guest editorial, "From 2020 Vision: An Engineering Education That Honors the Whole," is a thought experiment that calls us to envision how our community might respond after experiencing this pandemic. As you read this and the other articles in this issue, let us try to envision the future of engineering education in which we can all learn and thrive. During these trying times, we at JEE are trying. We are doing the best we can to respond to the 
challenging circumstances of this pandemic in a way that respects what our community-and our planet-are experiencing. Stay safe and healthy!

Lisa Benson ${ }^{1}$

Cindy Finelli ${ }^{2}$

Nadia Kellam ${ }^{3}$

Sarah Zappe ${ }^{4}$

${ }^{1}$ Clemson University, Clemson, South Carolina

${ }^{2}$ University of Michigan, Ann Arbor, Michigan

${ }^{3}$ Arizona State University, Mesa, Arizona

${ }^{4}$ Pennsylvania State University, University Park, Pennsylvania

Correspondence

Lisa Benson, Clemson University, Clemson, SC

Email: lbenson@clemson.edu

\section{REFERENCES}

American Society for Engineering Education [@ASEE_DC]. (2020, May 22). ASEE responds to recent comments from @purduemitch, where he appeared to call into question the integrity and scholarship of @PurdueENE [Tweet]. Twitter. https://twitter.com/ASEE_DC/status/ $1263808999071285248 /$ photo/1

Flaherty, C. (2020, May). The "right not to work." Inside Higher Ed. Retrieved from https://www.insidehighered.com/news/2020/05/04/ plans-fall-assume-professors-will-be-willing-teach-will-they

Weliever, A. (2020, May 21). Daniels minimizes prof's fall concerns in CNN interview. The Exponent. Retrieved from https://www. purdueexponent.org/campus/article_d6fa9f2c-9ae5-11ea-b954-63272a684b52.html 